\title{
Procyclicality of Capital Requirements in a General Equilibrium Model of Liquidity Dependence*
}

\author{
Francisco Covas $^{\dagger}$ and Shigeru Fujita ${ }^{\ddagger}$ \\ This version: May 2010 \\ First version: September 2009
}

\begin{abstract}
This paper quantifies the procyclical effects of bank capital requirements in a general equilibrium model where financing of capital goods production is subject to an agency problem. At the center of this problem is the interaction between entrepreneurs' moral hazard and liquidity provision by banks as analyzed by Holmstrom and Tirole (1998). We impose capital requirements under the assumption that raising funds through bank equity is more costly than through deposits. We consider the time-varying capital requirement (as in Basel II) as well as the constant requirement (as in Basel I). Importantly, under both regimes, the cost of issuing equity is higher during downturns. Comparing output fluctuations under the Basel I and Basel II economies with those in the no-requirement economy, we show that capital requirements significantly contribute to magnifying output fluctuations. The procyclicality is most pronounced around business cycle peaks and troughs.
\end{abstract}

JEL codes: E32, G21, G28

Keywords: Procyclicality, capital requirements, general equilibrium

\footnotetext{
*This is a substantially revised version of the paper formerly titled: "Time-Varying Capital Requirements in a General Equilibrium Model of Liquidity Dependence." We are particularly grateful to Javiar Suarez for his constructive comments. We also thank the editor Rafael Repullo, Xavier Freixas, David Jones, Ryo Kato, Garey Ramey, Skander Van den Heuvel, and the participants of the EBC/CEPR conference on "Procyclicality and Financial Regulation" for helpful discussions and comments. Remaining errors are ours. The views expressed in this paper are ours and do not necessarily reflect the views of the Federal Reserve Board, the Federal Reserve Bank of Philadelphia, or the Federal Reserve System. This paper is available free of charge at www.philadelphiafed.org/research-and-data/publications/working-papers/.

${ }^{\dagger}$ Quantitative Risk Management Section, Division of Banking Supervision and Regulation, Board of Governors of the Federal Reserve System. E-mail: francisco.b.covas@frb.gov

${ }^{\ddagger}$ Research Department, Federal Reserve Bank of Philadelphia. E-mail: shfujita@gmail.com.
} 


\section{Introduction}

There has been a strong interest in understanding interactions between bank capital regulation and macroeconomic fluctuations among policy makers and academic researchers. The interest has become even stronger in the aftermath of the recent financial crisis. One of the key concerns, especially from a macroeconomic perspective, is that bank capital regulation can induce significant "procyclicality," meaning that bank capital regulation can amplify the macroeconomic fluctuations. The procyclical effect was recognized under the first bank capital regulation, i.e., Basel I, in which banks are required to hold a constant fraction of equity. The procyclicality issue has received significantly more attention under the so-called risk-sensitive regulation (Basel II). Under Basel II, the risk weight associated with each loan is negatively related to the borrower's credit quality; therefore, during an economic downturn when overall credit quality deteriorates, capital requirements become more stringent. This further limits banks' lending capacity. Our interest is to quantify the procyclical effects using a general equilibrium macroeconomic model.

There are many papers with similar interests. Blum and Hellwig (1995) examine the procyclical effects of fixed capital requirements under Basel I. Using a simple reduced-form macroeconomic framework, they argue that it is likely to amplify macroeconomic fluctuations. Heid (2007) goes one step further by studying the implications of risk-sensitive capital requirements in a similar reduced-form environment. More recently, Zhu (2008) studies the effects of bank capital regulation on banks' behavior by applying the industry model of Cooley and Quadrini (2001) to a banking sector that is subject to risk-sensitive capital requirements. Finally, Repullo and Suarez (2009) develop a micro-founded partial equilibrium model of relationship banking and analyze the banks' behavior under risk-sensitive capital requirements. They show that the procyclicality under Basel II can be sizable.

Relative to these previous studies, we examine the business cycle implications of bank capital requirements in a general equilibrium macroeconomic model. Using a general equilibrium framework allows us to quantify the impact of bank capital regulation on macroeconomic variables. In our model, the financing of capital goods production is subject to an agency problem, as in Carlstrom and Fuerst (1997). The financing problem, however, is characterized by entrepreneurs' moral hazard and liquidity provision by financial intermediaries. This framework is proposed by Holmstrom and Tirole (1998) and adapted by Kato (2006) to a DSGE environment. We extend Kato's work along several dimensions so that we can examine the quantitative impact of bank capital regulation. We are aware that there are several alternative approaches. The first alternative would be the costly state verification framework developed by Townsend (1979) and popularized in macroeconomics by Bernanke and Gertler (1989), Carlstrom and Fuerst (1997), and Bernanke et al. (1999). The second alternative is the double moral hazard framework of Holmstrom and Tirole (1997) that is adapted to the macroeconomic environment by Chen (2001) and Meh and Moran (2010). ${ }^{1}$ We have adopted the framework of Holmstrom and Tirole (1998), because the model generates countercyclical

\footnotetext{
${ }^{1}$ In addition to entrepreneurs' moral hazard, this framework features moral hazard of the banking sector with respect to project monitoring, thus endogenously generating fluctuations in the bank capital ratio. However, Chen (2001) and Meh and Moran (2010) do not model regulatory requirements.
} 
liquidity dependence; firms tend to rely more heavily on lines of credit to finance their liquidity needs during downturns; and this countercyclical liquidity dependence underscores the important role banks play in an economy. The importance of credit lines in bank financing is very well known. For instance, loans made under a credit line amount to almost $80 \%$ of total C\&I loans. ${ }^{2}$ As Schuermann (2009) mentions, during economic downturns, market finance becomes scarce, and firms increase their liquidity dependence on banks by drawing down the loan commitments prearranged with banks. ${ }^{3}$ These empirical observations have led us to use the liquidity dependence framework instead of other popular frameworks mentioned above. This paper attempts to quantify the interaction between liquidity dependence and bank capital regulation.

We impose bank capital requirements assuming that raising funds through equity is more costly than through deposits, as in Repullo and Suarez (2009). We assume that the capital requirement ratio increases inversely with the business cycle under Basel II while it is fixed at a prespecified level of $8 \%$ under Basel I. Another key ingredient of our paper is the assumption that equity issuance is more costly in recessions. It is well known that new equity issuance during a downturn can be very costly. ${ }^{4}$ More generally speaking, as noted by Kashyap and Stein (2004), bank equity becomes scarcer in downturns, raising its (shadow) cost. By introducing the time-varying equity issuance cost, we distinguish between the two regulatory regimes depending on whether only the equity issuance cost is time varying (Basel I) or both the equity issuance cost and the capital requirement ratio are time varying (Basel II). Adopting these parsimonious specifications allows us to assess the procyclicality effects in a stylized DSGE environment.

The model is calibrated by using relevant observable information such as the utilization rate of credit lines. We specify the time-varying capital requirement in our model by using the actual Basel II risk-weight formula. To calibrate the equity issuance cost variable, we utilize the evidence by Kashyap and Stein (2004) that the additional cyclical pressure on bank capital positions under Basel II is of almost the same order of magnitude as the effect under Basel I. Further, we also consider cases in which the equity issuance cost responds more sharply to the business cycles. This is motivated by Repullo and Suarez (2009)'s claim that the shadow cost of bank equity can be very high at the time of financial distress. It is shown that, across various plausible calibrations, Basel I and Basel II contribute to increasing the standard deviation of output fluctuations by around 5 basis points and 10 basis points, respectively. We argue that these "average" effects hide important differences in the paths of aggregate output which occur around business-cycle peaks and troughs. For example, around the bottom of business cycles, output in the Basel I economy can be lower than that in the no-requirement economy by $10-15$ basis points. This magnification effect can be as large as 20-40 basis points when the Basel II economy is compared with the no-requirement economy.

Qualitatively speaking, the procyclicality in our model is driven by the feature that capital

\footnotetext{
${ }^{2}$ See the Survey of Terms of Business Lending (FRB E.2 Release).

${ }^{3}$ There are several papers on the importance of loan commitments for bank risk management and corporate liquidity management. See, for example, Kashyap et al. (2002) and Sufi (2009), respectively.

${ }^{4}$ See, for example, the discussions and references in Repullo and Suarez (2009).
} 
requirements directly affect the bank's ability to provide lines of credit to entrepreneurs. Under Basel II, when the availability of lines of credit is more valuable (during downturns), the cost of making those loans is higher as a result of the higher capital requirement: A more strict capital requirement implies that it is more difficult for the bank to meet entrepreneurs' financing needs and, consequently, more positive NPV projects (that would otherwise be implemented) are destroyed. The same mechanism works when the equity issuance cost rises

during downturns. Banks face both of the two constraints under Basel II, whereas only the time-varying equity issuance cost induces procyclicality under Basel I.

While our main focus is on the volatility effects of capital requirements, we also look at the steady-state effects of a permanently higher capital requirement ratio. Since our model omits any welfare-improving aspects of capital requirements, the higher capital requirement necessarily entails only negative effects on the macroeconomy. Having recognized this limitation, the transition dynamics to the new steady state exhibit some interesting patterns among macro variables. First, our model naturally implies that output, consumption, and investment all converge to permanently lower levels. However, before reaching this new steady state, investment goes down significantly more in the first few years, while household consumption increases: The higher capital requirement reduces the supply of capital goods, causing the price of capital goods to rise over time, and this induces the substitution into consumption away from savings (investment) in the short run.

This paper proceeds as follows. In Section 2, we describe our model. In Section 3, we calibrate the model. Section 4 focuses on the effects of changes in the capital requirement without the aggregate productivity shock. Section 5 presents the main result of the paper, namely the business-cycle implications of Basel I and Basel II. We show that the procyclical effects of these regulations can be sizable. We also touch on the idea of "countercyclical regulation" within our model. Section 6 concludes the paper.

\section{Model}

The model structure is similar to that in Kato (2006), who provides an important alternative to Carlstrom and Fuerst (1997) and Bernanke et al. (1999) in modeling the financial frictions in macroeconomic models. The latter two papers embed costly state verification (CSV) into an otherwise-standard RBC model. Instead of CSV, Kato (2006) adopts the financial contract developed by Holmstrom and Tirole (1998), who emphasize the importance of liquidity provision by financial intermediaries and its interaction with entrepreneurs' moral hazard. We deviate from Kato (2006) in the following two ways. First, we allow for non-zero liquidation value when projects are abandoned. The second, which is the focus of our paper, is that we impose capital requirements on financial intermediaries.

\subsection{Environment}

The economy is populated by four types of agents: a fixed mass $1-\eta$ of households, a fixed mass $\eta$ of entrepreneurs, banks, and firms. Both households and entrepreneurs supply labor 
Table 1: Sequence of Events Within a Period

1. The aggregate technology shock $(\epsilon)$ is realized.

2. Firms hire labor and rent capital from households and entrepreneurs and produce the consumption good.

3. Households earn their labor and capital income and make the consumption-saving decision.

4. Banks use the resources obtained from households to provide loans to entrepreneurs. The optimal contract is described in Subsection 2.2.

5. Entrepreneurs borrow $i-n$ consumption goods from the bank and place all of them together with their entire net worth $n$ into capital-creation projects.

6. The idiosyncratic liquidity shocks $(\omega)$ are realized. Projects with $\omega \leq \bar{\omega}$ are financed through credit lines. Otherwise, projects are abandoned and the bank obtains the liquidation value of $\tau i$.

7. Outcomes of the continued projects are realized. The entrepreneurs with successful projects distribute a part of the return to the bank.

8. Entrepreneurs make the consumption-saving decision.

and rent out capital to the firms that produce the consumption good. Entrepreneurs differ from households with respect to their ability to produce the capital good. Entrepreneurs borrow funds from the banks, which funnel households' savings. The intermediation is subject to the agency problem of Holmstrom and Tirole (1998). Further, banks are also constrained by the capital requirement. The sequence of events, which is similar to that in Carlstrom and Fuerst (1997), is summarized in Table 1.

\subsection{Financial Contract}

The financial contract starts and ends within a period. The general equilibrium of the economy influences the contract only through the level of net worth $n$ and the price of capital $q$. These variables are thus treated parametrically in this subsection.

The contract involves two parties, a bank and an entrepreneur. Both parties are risk neutral. Entrepreneurs are endowed with technology that converts the consumption good into the capital good. Let $i$ be the investment size (measured in the consumption good), which yields $R i$ units of the capital good, when the project is successful. ${ }^{5}$ The success probability is $p_{j}$ where $j \in\{H, L\}$. The entrepreneur, whose net worth is $n$, borrows $i-n$ units of the consumption good from the bank.

The project proceeds in three stages $(0,1$, and 2$)$. At stage 0 , the investment $(i)$ is put in place. At stage 1, the exogenous "liquidity shock," $\omega \in[0, \infty)$, is realized. The shock $\omega$ measures a per-unit-of-investment liquidity infusion (in units of the capital good) that is necessary to continue the project. $\omega$ is assumed to be i.i.d. cross-sectionally and over

\footnotetext{
${ }^{5}$ When it fails, the return is zero.
} 
time, and distributed according to $\Phi(\omega)$ with density $\phi(\omega)$. Without the cash infusion, the project is abandoned and liquidated. When the project is abandoned, the salvage value, $\tau i$, is transferred to the lender. ${ }^{6}$ The last stage, in which the project is actually undertaken, is subject to moral hazard of the entrepreneur. He can exert effort or shirk. Exerting effort yields the success probability of $p_{H}$ and no private benefit and shirking results in the lower success probability of $p_{L}\left(<p_{H}\right)$ and yields a private benefit of $B i$.

As Holmstrom and Tirole (1998) show, socially optimal financing in this environment is characterized by the cutoff rule that the project is abandoned if and only if $\omega \geq p_{H} R \equiv \omega_{1}$. This level of the liquidity shock is called the first best cutoff.

Capital requirements and equity issuance cost. The bank can raise funds through either deposits or equity (e), but holding equity involves the equity issuance cost $c$. We assume for analytical convenience that this cost is linear with respect to the size of equity issuance:

$$
c=\gamma(A) e,
$$

where $\gamma(A)$ represents the per-unit cost of holding equity, which is assumed to depend on the aggregate economic condition. More specifically, we take the TFP process $(A)$ as representing this aggregate economic condition. The TFP process and the functional form for $\gamma(A)$ will be specified in the calibration section.

Under the presence of the equity issuance cost, the bank's zero profit condition can be written as follows.

$$
i-n+q i E(\omega \mid \omega \leq \bar{\omega}) \Phi(\bar{\omega})=q i \int_{0}^{\bar{\omega}} p_{H}\left(R-R^{e}(\omega)\right) \phi(\omega) d \omega+q i(1-\Phi(\bar{\omega})) \tau-c,
$$

where the left-hand side represents the total number of loans (i.e., the sum of initial project loans and credit lines in the middle stage). On the right-hand side, $R^{e}$ is the return to the entrepreneur, and thus the first term represents the expected return to the bank. The second term gives the liquidation value when the project is terminated, and the last term gives the equity issuance cost. The bank is, by regulation, required to maintain a certain level of equity; the regulator imposes the "capital requirement" in terms of the size of equity relative to the total number of loans, which is written as:

$$
e=\theta(A)[i-n+q i E(\omega \mid \omega \leq \bar{\omega}) \Phi(\bar{\omega})]
$$

where $\theta(A)$ is the capital requirement ratio, which can depend on the aggregate TFP process. Note that because equity is more costly than deposits, the capital requirement holds with equality, which is imposed in Equation (3). Combining Equations (1), (2), and (3) results in

$$
[1+\Theta(A)][i-n+q i E(\omega \mid \omega \leq \bar{\omega}) \Phi(\bar{\omega})]=q i \int_{0}^{\bar{\omega}} p_{H}\left(R-R^{e}(\omega)\right) \phi(\omega) d \omega+q i(1-\Phi(\bar{\omega})) \tau,
$$

\footnotetext{
${ }^{6}$ Kato (2006) assumes that the liquidation value is zero. In contrast, we allow for a positive liquidation value and the parameter $\tau$ is calibrated referring to the empirical evidence.
} 
where $\Theta(A) \equiv \theta(A) \gamma(A)$. Our main interest is to examine the procyclical effects of the two forms of capital requirements (i) flat requirement in which $\theta$ is fixed regardless of the aggregate condition and (ii) a "procyclical" requirement in which $\theta$ is higher (lower) during downturns (booms). Each of the two capital requirement schemes is intended to mimic the capital requirement under Basel I and Basel II, respectively. Note also that regardless of which regime the economy is in, the time-varying feature of the equity issuance cost is maintained.

We would like to stress here a few issues regarding our modeling strategy for the capital requirements and the equity issuance cost. In our model, banks are perfectly competitive intermediaries that simply channel funds from households to capital-producing entrepreneurs. Operating this service per se does not require bank equity and the requirement of holding a certain level of bank equity is modeled simply as a "tax" on financial intermediation. Furthermore, we impose this cost exogenously, meaning that regulation plays no useful role in the economy. That is, since the intra-period financial contract is, by construction, not subject to the aggregate risk, the bank failure never occurs in our model. The bank capital requirement thus plays no role in this regard. ${ }^{7}$ Another way to motivate capital regulation is to consider an environment like the one considered by Van den Heuvel (2008), in which the capital requirement plays the role of mitigating the bank's moral hazard created by deposit insurance. We leave these important issues aside, given that our main interest is on quantifying the volatility effects.

We also make an assumption that the equity issuance cost fluctuates exogenously over the business cycle. More specifically, we assume the $\gamma^{\prime}(A)<0$. It seems quite plausible that the cost of maintaining a certain level of bank equity is countercyclical. It is well known that issuing equity is much more expensive during recessions (see Repullo and Suarez (2009)). More generally, Kashyap and Stein (2004) argue that bank capital becomes scarcer during bad times, raising the "shadow cost of capital." 8 This scarcity reflects the fact that higher loan losses and lower operating income deplete the stock of bank capital more rapidly during recessionary times. Ideally, we would like to endogenously incorporate this feature into the model. However, our model is arguably too stylized and thus we take a shortcut. ${ }^{9}$ In Section 3 below, we will discuss more specific features of this exogenous process.

Optimal contract. The optimal contract maximizes the entrepreneur's expected payoffs by choosing (i) the size of the project $i$, (ii) the return to the entrepreneur, $R^{e}$ when the project is successful, ${ }^{10}$ and (iii) the cutoff liquidity shock $(\bar{\omega})$. The problem is subject to the

\footnotetext{
${ }^{7}$ One could imagine a model with an inter-period contract that cannot be contingent on aggregate risk. In such an environment, bank capital requirements can play the role of avoiding bank failure.

${ }^{8}$ See also the references therein for further discussion of this point.

${ }^{9}$ Covas and Den Haan (2010) also specify a similar exogenous process for the equity issuance cost to analyze debt and equity finance over the business cycle, although their focus is on the behavior of the nonfinancial corporate sector.

${ }^{10}$ This is equivalent to choosing the division of the total return $R$ between the two parties.
} 
bank's break-even constraint and the entrepreneur's incentive compatibility constraint: ${ }^{11}$

$$
\max q i \int_{0}^{\bar{\omega}} p_{H} R^{e}(\omega) \phi(\omega) d \omega-n,
$$

subject to Equation (4) and the entrepreneur's incentive compatibility constraint,

$$
p_{H} R^{e}(\omega) \geq p_{L} R^{e}(\omega)+B
$$

Observe that in the problem above, the return to the entrepreneur is allowed to be contingent on $\omega$. However, as Holmstrom and Tirole (1998) show, Equation (6) binds in the optimal contract and thus the dependence of the return to the entrepreneur on $\omega$ vanishes, i.e., $R^{e}(\omega)=\frac{B}{p_{H}-p_{L}}$. This result arises because it is optimal that the entrepreneur borrow as much as possible up to the so-called "borrowing limit," which is in turn achieved by the borrower taking the minimum payment necessary to exert high effort. The return to the lender is then written as $p_{H}\left(R-\frac{B}{p_{H}-p_{L}}\right) \equiv \omega_{0}$, which is called pledgeable income. Using the binding incentive compatibility constraint, Equation (6), in Equation (4) results in:

$$
i=\frac{1}{1-q h(\bar{\omega}, \Theta(A))} n
$$

where

$$
h(\bar{\omega}, \Theta(A))=\frac{\Phi(\bar{\omega}) \omega_{0}+(1-\Phi(\bar{\omega})) \tau}{1+\Theta(A)}-E(\omega \mid \omega \leq \bar{\omega}) \Phi(\bar{\omega}) .
$$

These expressions make clear that investment is directly influenced not only by net worth and the price of capital as in Kato (2006) but also by the capital requirement ratio and the cost of bank equity. Using Equation (7) in Equation (5) and maximizing the resulting expression with respect to $\bar{\omega}$ results in the following first-order condition:

$$
q \int_{0}^{\bar{\omega}} \Phi(\omega) d \omega=1-\frac{q \tau}{1+\Theta(A)} .
$$

We can solve this optimality condition for the cutoff liquidity shock $\bar{\omega}$, given the levels of $q$ and $\Theta(A)$.

As in Kato (2006), we define the degree of liquidity dependence as follows:

$$
\text { Liquidity dependence } \equiv \frac{i \int_{0}^{\bar{\omega}} \omega d \Phi(\omega)}{i p_{H} R \Phi(\bar{\omega})}=\frac{E(\omega \mid \omega \leq \bar{\omega})}{\omega_{1}} .
$$

Equation (10) captures the dependence on the bank's liquidity provision relative to the size of investment. In Kato (2006) where $\tau=0$ and $\Theta(A)=0$, the second term in the right-hand side of Equation (9) drops out, and it is particularly simple to see in that case that $q$ and $\bar{\omega}$ are negatively related. The negative relationship then implies countercyclical liquidity dependence in Equation (10) (given that $q$ is procyclical). As we will see later,

\footnotetext{
${ }^{11}$ Note that a binding capital requirement is a priori imposed below.
} 
the countercyclical liquidity dependence will also be true in our model. Note, however, that Equation (9) alone cannot tell how changes in $\Theta$ influence $\bar{\omega}$ and thus liquidity dependence. ${ }^{12}$ To assess this effect, we will later consider an experiment of changing $\Theta$ without changing $A$ and see how other endogenous variables respond to it. There we will see that higher $\Theta$ causes the supply of funds to drop and thus raises the price of capital. When the price of capital is higher, $\bar{\omega}$ and thus liquidity dependence go down.

\section{$2.3 \quad$ Households}

The representative household maximizes the discounted sum of their utility derived from consumption $\left(c_{t}\right)$ and leisure $\left(l_{t}\right)$ :

$$
E_{0} \sum_{t=0}^{\infty} \beta^{t} u\left(c_{t}, l_{t}\right),
$$

where $\beta$ is the discount factor. As in Carlstrom and Fuerst (1997) and Kato (2006), we assume that the utility function is additively separable in consumption and leisure, and labor supply is indivisible:

$$
u\left(c_{t}, l_{t}\right)=\frac{c_{t}^{1-\psi}}{1-\psi}+\nu\left(1-l_{t}\right)
$$

where $\psi$ is the coefficient of relative risk aversion and $\nu$ is a normalizing constant. ${ }^{13}$ The decisions are subject to the following budget constraints:

$$
\begin{gathered}
c_{t}+s_{t}=r_{t} k_{t}+w_{t}\left(1-l_{t}\right), \\
k_{t+1}=(1-\delta) k_{t}+\frac{1}{q_{t}} s_{t},
\end{gathered}
$$

where $s_{t}$ is the household saving at the bank, $k_{t}$ is the capital stock held by the household, $w_{t}$ and $r_{t}$ are, respectively, wage and interest rates paid by the firm, and $\delta$ is the depreciation rate of the capital stock. The first-order conditions to this problem are written as follows:

$$
\begin{gathered}
q_{t}=\beta E_{t}\left(\frac{c_{t}}{c_{t+1}}\right)^{\psi}\left[r_{t+1}+(1-\delta) q_{t+1}\right], \\
-\nu c_{t}^{\psi}=w_{t} .
\end{gathered}
$$

Note that the proportion $\theta$ of the household saving $s_{t}$ is held as "bank equity," and the rest as "deposits." From the household's standpoint, however, the portfolio choice is irrelevant because either asset yields gross interest of unity. This outcome is supported by the assumption that the financial contract starts and ends within the same period.

\footnotetext{
${ }^{12}$ In particular, Equation (9) does not imply that nonzero $\tau$ is necessary for the capital requirement to have any effects in the model. For example, Equations (7) and (8) indicate that $\Theta$ directly affects the relationship between net worth and investment, which in turn comes from the effect of $\Theta$ on the bank's balance sheet (Equation (4)).

${ }^{13}$ Our results below are not sensitive to the choice of the functional form. For instance, we have experimented with cases where the utility function is non-separable and where labor supply is divisible, and obtained results similar to those reported below.
} 


\subsection{Entrepreneurs}

In modeling the behavior of entrepreneurs, we make several assumptions similar to those in Carlstrom and Fuerst (1997), which are also adopted by Kato (2006). First, they are riskneutral. Second, they discount the future more heavily $\left(\beta^{e}<\beta\right)$ than the households. This latter assumption is to avoid the self-financing equilibrium. That is, absent this assumption, entrepreneurs quickly accumulate enough wealth by postponing consumption, so that the project can be financed through internal funds only. By lowering the discount factor for them, we prevent this self-financing equilibrium from arising. ${ }^{14}$ The third assumption is that entrepreneurs supply labor inelastically to the firm.

The entrepreneur maximizes the discounted sum of their utility derived from consumption $\left(c_{t}^{e}\right)$ :

$$
E_{0} \sum_{t=0}^{\infty}\left(\beta^{e}\right)^{t} c_{t}^{e}
$$

As described in Table 1, the entrepreneur first receives labor and capital incomes from the consumption goods sector at the start of each period. He then enters into the financial contract with net worth $n_{t}$ :

$$
n_{t}=(1-\delta) q_{t} z_{t}+r_{t} z_{t}+w_{t}^{e}
$$

where $z_{t}$ is the capital stock held by the individual entrepreneur, and $w_{t}^{e}$ is the wage payment to the entrepreneur. The entrepreneur's net worth consists of the undepreciated part of the capital stock and the two flow incomes from the consumption goods sector. That the entrepreneur earns labor income is important because it allows the entrepreneur to enter into the financial contract with non-zero net worth even when he starts with zero capital stock. ${ }^{15}$ When the entrepreneur withstands the liquidity shock (i.e., $\omega \leq \bar{\omega}$ ) and the project turns out to be successful, the consumption-saving decision is subject to the following constraint:

$$
c_{t}^{e}+q_{t} z_{t+1}=\frac{q_{t} R^{e}}{1-q_{t} h\left(\bar{\omega}_{t}, \Theta\left(A_{t}\right)\right)} n_{t} .
$$

The right-hand side of Equation (19) represents the total return to the entrepreneur. The numerator gives the per-project return and the remaining term gives the size of investment as a multiple of his net worth, which was derived in Equation (7). These entrepreneurs' consumption-saving decision obeys the following Euler equation:

$$
q_{t}=\beta^{e} E_{t}\left[q_{t+1}(1-\delta)+r_{t+1}\right] \frac{q_{t+1}\left(\omega_{1}-\omega_{0}\right) \Phi\left(\bar{\omega}_{t+1}\right)}{1-q_{t+1} h\left(\bar{\omega}_{t+1}, \Theta\left(A_{t+1}\right)\right)} .
$$

\footnotetext{
${ }^{14}$ The alternative way to avoid this situation is to assume that a certain fraction of entrepreneurs die each period and sell their accumulated wealth to the household. See, for example, Carlstrom and Fuerst (1997) and Bernanke et al. (1999) for more details.

${ }^{15} \mathrm{He}$ starts the current period with no capital stock when the project was abandoned or failed in the previous period.
} 
When the project is abandoned or unsuccessful, the entrepreneur gets nothing; thus, $c_{t}^{e}=$ $z_{t+1}=0$. Note that the entrepreneur's project succeeds with probability $p_{H} \Phi\left(\bar{\omega}_{t}\right)$. Aggregating the capital stocks held by $\eta$ entrepreneurs, we can write:

$$
Z_{t+1}=\frac{\left(\omega_{1}-\omega_{0}\right) \Phi\left(\bar{\omega}_{t}\right)}{1-q_{t} h\left(\bar{\omega}_{t}, \Theta\left(A_{t}\right)\right)} \eta n_{t}-\frac{\eta c_{t}^{e}}{q_{t}},
$$

where $Z_{t+1}$ is the aggregate capital stock held by the entrepreneurial sector.

\section{$2.5 \quad$ Firms}

The representative firm produces the consumption good by using the following constantreturns-to-scale technology:

$$
Y_{t}=A_{t} K_{t}^{\alpha} H_{t}^{\iota} J_{t}^{1-\alpha-\iota}
$$

where $A$ is TFP, $K$ is aggregate capital stock, $H$ is labor supply by the household sector, and $J$ is labor supply by the entrepreneurial sector. TFP evolves according to the following $\mathrm{AR}(1)$ process:

$$
\ln A_{t+1}=\rho \ln A_{t}+\epsilon_{t+1} .
$$

The technology shock $\epsilon_{t}$ is distributed as standard normal $N\left(0, \sigma_{\epsilon}\right)$. Labor and capital rental markets are assumed to be competitive. The firm thus hires two types of labor and rents capital according to: $r_{t}=\alpha A_{t} K_{t}^{\alpha-1} H_{t}^{\iota} J_{t}^{1-\alpha-\iota}, w_{t}=\iota A_{t} K_{t}^{\alpha} H_{t}^{\iota-1} J_{t}^{1-\alpha-\iota}$, and $w_{t}^{e}=$ $(1-\alpha-\iota) A_{t} K_{t}^{\alpha} H_{t}^{\iota} J_{t}^{-\alpha-\iota}$.

\subsection{General Equilibrium}

The following market-clearing conditions close the model:

$$
\begin{gathered}
H_{t}=(1-\eta)\left(1-l_{t}\right) \\
J_{t}=\eta \\
Y_{t}=(1-\eta) c_{t}+\eta c_{t}^{e}+\eta i\left(1+q_{t} E(\omega \mid \omega \leq \bar{\omega}) \Phi(\bar{\omega})+q_{t} \frac{\Theta\left(A_{t}\right) \Phi\left(\bar{\omega}_{t}\right) \omega_{0}-\left(1-\Phi\left(\bar{\omega}_{t}\right)\right) \tau}{1+\Theta\left(A_{t}\right)}\right) \\
K_{t+1}=(1-\delta) K_{t}+\eta i \omega_{1} \Phi\left(\bar{\omega}_{t}\right) .
\end{gathered}
$$

The first two equations above clear the two labor markets, the third equation clears the market for the consumption good, and the last equation clears the market for the capital good. The last term in Equation (25) properly accounts for the resource cost of the capital requirement net of the liquidation value of the failed projects.

\section{Calibration}

We now discuss the baseline calibration of the model. One period in the model is assumed to be one quarter. The parameter values used in our baseline calibration are summarized in Table 2 . 


\subsection{Parameters Set Externally}

The discount factor for the household $(\beta)$ is set equal to 0.99 . The discount factor for the entrepreneur $\left(\beta^{e}\right)$ needs to be set to a lower value to avoid the self-financing equilibrium and is selected to be 0.94. This value is commonly used in this literature (e.g., Carlstrom and Fuerst (1997)). The CRRA parameter of the household $(\psi)$ is set to 1.5. The firm's production technology is Cobb-Douglas, as shown in (21), with the capital share $\alpha$ equal to 0.33, the household's labor share $\iota$ equal to 0.66, and the entrepreneur's labor share equal to $0.01 .{ }^{16}$ These numbers are all in line with the previous literature. The depreciation rate of the capital stock $\delta$ is 0.025 . The aggregate TFP process $\left(A_{t}\right)$ is assumed to have the persistence parameter $\rho$ equal to 0.95 and the conditional standard deviation $\sigma$ equal to 0.007. Finally, we set the fraction of entrepreneurs in the population $\eta$ to 0.3 as in Kato $(2006) \cdot{ }^{17}$

\subsection{Parameters Set Internally}

First, the normalizing parameter $\nu$ of the labor supply function is chosen to be 2.68 , such that the household spends one-third of its time on working, given all other parameter values. We assume that the distribution of liquidity shocks $\Phi(\omega)$ is lognormal with mean equal to one and a standard deviation of $\sigma_{\omega}{ }^{18}$ We assign $\sigma_{\omega}$ together with the three parameters, the first-best cut-off $\omega_{1}$, the pledgeable return from the investment $\omega_{0}$, and the liquidation value parameter $\tau$, to match the following four moments from the data: (i) loss given default (LGD) on bank loans; (ii) probability of default (PD); (iii) utilization rate on lines of credit; and (iv) the ratio of unused commitments to total loans. These four moments are summarized in Table 3.

LGD. First, note that Moody's and S\&P have databases with recovery rates for various debt instruments. However, most of the defaults in these two databases are for corporate bonds and not for bank loans. There are various differences between these two instruments, and in particular, corporate bonds are unsecured and bank loans are often secured loans at the time of default. This results in significant differences in average recovery rates. Specifically, corporate bonds have significantly lower recovery rates compared to bank loans. We thus make use of the information provided by Araten et al. (2004) to calibrate average LGD. This study was based on the default experience of a single large U.S. bank in the period between 1982 and 1999. Given the large size of this bank's portfolio, we believe that this series is more representative than the information based on a limited number of defaulted

\footnotetext{
${ }^{16}$ Note that the small share is chosen, so that entrepreneurs enters into the financial contract with at least some wealth. See Carlstrom and Fuerst (1997) and the discussion in Subsection 2.4.

${ }^{17}$ This parameter has little impact on the aggregate behavior of our model; we experimented with the case of $\eta=0.2$ and found that the model's aggregate properties changed little. See Dorefeenko et al. (2008), who show that this parameter works simply as "normalization" in the Carlstrom and Fuerst (1997) model. In footnote 7 and the Appendix of that paper, they spell out this issue in detail.

${ }^{18}$ The mean of the distribution is set to one as normalization. In principle, we could use either the steady-state level of the price of capital or the mean as normalization.
} 
Table 2: Baseline Calibration

\begin{tabular}{lcr}
\hline \hline Discount factor of households & $\beta$ & 0.99 \\
Discount factor of entrepreneurs & $\beta^{e}$ & 0.94 \\
Relative risk aversion of households & $\psi$ & 1.50 \\
Labor supply parameter & $\nu$ & 2.68 \\
Capital share & $\alpha$ & 0.33 \\
Household labor share & $\iota$ & 0.66 \\
Depreciation rate & $\delta$ & 0.025 \\
S.D of liquidity shock & $\sigma_{\omega}$ & 0.44 \\
First best cut-off & $\omega_{1}$ & 2.75 \\
Pledgeable income & $\omega_{0}$ & 1.93 \\
Recovery rate parameter & $\tau$ & 0.60 \\
Mean level of the capital requirement & $\theta_{0}$ & 0.08 \\
Elasticity of the capital requirement & $\theta_{1}$ & -8 \\
Mean level of the equity issuance cost & $\gamma_{0}$ & 0.05 \\
Elasticity of the equity issuance cost & $\gamma_{1}$ & -8 \\
Persistence of aggregate TFP shock & $\rho$ & 0.95 \\
S.D. of aggregate TFP shock & $\sigma$ & 0.007 \\
\hline \hline
\end{tabular}

Notes: Under the flat capital requirement (Basel I) regime, the dependence of the capital requirement ratio on aggregate TFP is suppressed, i.e., $\theta_{1}=0$.

bank loans available in the Moody's or S\&P databases. The average LGD of this bank over this 18 -year period is $39.8 \%$. We target this value in the steady state by associating it with the following concept in the model:

$$
\mathrm{LGD}=1-\frac{\tau q i}{i-n},
$$

where the second term in the right-hand side is the recovery rate of the initial bank loan.

PD. For the empirical default rate, we rely on the default-rate series published by Moody's that covers the period between 1982 and 2004. In Moody's data, the average default rate over the 22 -year period is $0.50 \%$ per quarter, which is taken to be our target. In the model, the corresponding default rate is simply the probability that the liquidity shock $\omega$ is higher than the cutoff value $\bar{\omega}{ }^{19}$

\footnotetext{
${ }^{19}$ Recall that, in our model, entrepreneurs' projects can fail with probability $1-p_{H}$ even after the projects survive the liquidity shock. This variable $p_{H}$, however, does not need to be separately calibrated; this
} 
Table 3: Selected Moments: Data vs. Model

\begin{tabular}{lrr}
\hline \hline Moments & Data (\%) & Model (\%) \\
\hline LGD & 39.8 & 35.4 \\
PD & 0.5 & 0.6 \\
Utilization rate of credit lines & 32.5 & 36.0 \\
Ratio of unused commitments over total loans & 86.0 & 91.5 \\
\hline \hline
\end{tabular}

Notes: LGD (loss given default) equals the ratio of the amount of losses to loans outstanding at the time of default. The reported number is an average over 1982 through 1999 for a large U.S. bank, reported by Araten et al. (2004). PD (the probability of default) is from Moody's default rate series. The reported number is an average over 1982 through 2004. The utilization rate is equal to the ratio of used revolving credits over the committed amount. It is taken from Sufi (2009), who uses a sample of 300 firms with debt outstanding over 1996 through 2003. The ratio of unused commitments to total loans is calculated from the series in call reports, RCFD3423 and RCFD1400, which cover all U.S. commercial banks over 1990 through 2004.

Utilization rate. We use the evidence gathered by Sufi (2009) to calibrate the average ratio of the used amount of the credit line to the committed amount. For a sample of 300 firms with debt outstanding, the average utilization rate is $32.5 \%$ over the period 1996 through 2003. This evidence is taken to be our target. In the model, we can define the utilization rate as follows:

$$
\text { Utilization rate }=\frac{\int_{0}^{\bar{\omega}} \omega d \Phi(\omega)}{\bar{\omega} \Phi(\bar{\omega})}=\frac{E(\omega \mid \omega \leq \bar{\omega})}{\bar{\omega}} .
$$

Unused commitments. The ratio of unused commitments to total loans is available on the regulatory fillings of all commercial banks. The information is collected as part of the call reports. The sample period for this series is 1990 through 2004. The average ratio of unused commitments over this period amounts to $86 \%$. In the model, this ratio is defined as follows:

$$
\text { Ratio of unused commitments }=\frac{q i \int_{0}^{\bar{\omega}}(\bar{\omega}-\omega) d \Phi(\omega)}{i-n+q i \int_{0}^{\bar{\omega}} \omega d \Phi(\omega)}=\frac{q i[\bar{\omega}-E(\omega \mid \omega \leq \bar{\omega})] \Phi(\bar{\omega})}{i-n+q i E(\omega \mid \omega \leq \bar{\omega}) \Phi(\bar{\omega})} \text {. }
$$

Table 3 presents the steady-state performance in matching these four moments. While the model is unable to match these moments exactly, three moments appear reasonably close to their empirical counterparts.

variable is embedded in $\omega_{0}$ and $\omega_{1}$. In terms of interpretation, we assume implicitly that $p_{H}$ is very close to 1 . 


\subsection{Capital Requirements and Equity Insurance Cost}

It remains to specify the processes for the regulatory capital requirement $(\theta)$ and the equity issuance $\operatorname{cost}(\gamma)$. We assume that these variables follow simple log-linear functions of the TFP process $A_{t}$ :

$$
\begin{aligned}
\theta_{t} & =\theta_{0} A_{t}^{\theta_{1}}, \\
\gamma_{t} & =\gamma_{0} A_{t}^{\gamma_{1}},
\end{aligned}
$$

where $\theta_{0}, \theta_{1}, \gamma_{0}$, and $\gamma_{1}$ are the parameters to be calibrated. Putting these two costs together, we obtain

$$
\Theta_{t}=\theta_{0} \gamma_{0} A_{t}^{\theta_{1}+\gamma_{1}} .
$$

As we mentioned above, we consider two regulatory regimes; (i) the fixed capital requirement regime and (ii) the procyclical capital requirement regime. In the former regime, $\theta_{t}$ is fixed at $\theta_{0}$ and $\theta_{1}$ is set equal to zero. Thus, only the time-varying equity issuance cost is maintained. This regime mimics the Basel I regulation. In the latter regime, both variables are time varying. The time-varying capital requirement in this regime is intended to mimic the Basel II regulation.

Capital requirement ratio. Let us first discuss the calibration of the capital requirement ratio. Under the procyclical regulation regime, the capital requirement ratio increases (decreases) when the economy is in a downturn (boom), implying that $\theta_{1}<0$. We calibrate $\theta_{0}$ and $\theta_{1}$ by using the Basel II risk-weight formula. Note first that Basel II requires banks to calculate the risk weight for each loan based on the formula, which is detailed in the Appendix. Roughly speaking, the formula takes PD, LGD, and maturity of the loan and yields the risk weight for that loan. We calculate the average risk weight (i.e., the average capital requirement ratio) by using average values of these three variables. LGD is taken to be $40 \%$, a level consistent with the evidence mentioned before. Average maturity is taken to be 2.5 years. Last, we use the Moody's default rate series for PD. We then obtain a time series of the economy-wide risk weight over the period 1982 and 2004. This series fluctuates over time because of the time variations in the default rate series. We calibrate $\theta_{0}$ and $\theta_{1}$ to replicate the cyclical features of this series. Specifically, the aggregate risk-weight series has a mean level of $8 \%$ and volatility of 0.10 after applying the HP filter with smoothing parameter of 1,600 . We thus set $\theta_{0}$ to 0.08 . We also obtain $\theta_{1}=-8$ as a value that matches the volatility of the HP-filtered series. Under the fixed capital requirement regime, $\theta_{1}=-8$ is set equal to zero.

Equity issuance cost. The tight estimates for $\gamma_{0}$ and $\gamma_{1}$ are hard to come by. First, pinning down the mean level of this cost $\gamma_{0}$ is not straightforward. In the macro literature, Cooley and Quadrini (2001) assume that raising new equity involves a 30\% premium over debt financing. In an application of the same model to the banking sector, Zhu (2008) also uses the same value; he argues that, referring to Van den Heuvel (2009), the $30 \%$ premium (relative to deposit financing) is in line with the size of the tax burden on bank profits, which 
can be a part of bank equity. It is, however, somewhat misleading to apply this value to our model directly, because this estimate is supposed to be costs for new equity, whether in the form of bank profits or new equity issuance. While the parameter $\gamma_{0}$ in our model corresponds to the cost of issuing new equity, it seems naive to adopt the literal interpretation to calibrate this parameter because in reality banks do not issue new equity every period. Instead it seems more appropriate to interpret $\gamma$ as overall costs for maintaining a certain level of bank equity instead. This consideration leads us to reduce the value of this parameter to 0.05 . This implies that the presence of capital requirement increases the effective funding cost for the bank by $0.4 \%(=0.05 \times 0.08)$ on a quarterly basis.

To calibrate the elasticity parameter $\gamma_{1}$, we refer to the evidence provided by Kashyap and Stein (2004), in which they analyze the cyclicality of "capital charges," which represent the total amount of required bank capital. Based on their empirical results, they argue that the cyclical pressure on bank capital positions can be accounted for roughly equally by the higher requirement ratio induced by the Basel II risk-sensitive regulation and the higher shadow cost of capital. ${ }^{20}$ This finding leads us to set $\gamma_{1}=\theta_{1}=-8$ in the baseline calibration. However, their result is based on the observations between 1998-2002, the period which is arguably a calm period in terms of financial distress. As argued by Repullo and Suarez (2009), the shadow cost of bank equity can become very high during the time of financial distress. Therefore, we also consider the cases (as plausible alternatives), in which $\gamma_{1}$ is set to larger negative values $(-12$ and -15$)$.

\subsection{Solving the Model}

We solve the model nonlinearly by applying the projections PEA (parameterized expectation algorithm). Specifically, we parameterize the conditional expectations in the two Euler equations (15) and (20) by a tensor product of the Chebyshev polynomials of the three state variables $Z_{t}, K_{t}$, and $A_{t}$. Given the parameterized values of the expectations, we solve for all endogenous variables. We can then evaluate the conditional expectations and see if they are close to the initially postulated conditional expectations. We iterate on this process until the coefficients of the parameterized functions converge. ${ }^{21}$

\section{Effects of Higher Capital Requirement}

Before discussing our main results, this section focuses on the effects of a change in the capital requirement ratio while suppressing fluctuations of aggregate productivity. This

\footnotetext{
${ }^{20}$ More precisely, Kashyap and Stein (2004) write, "The added cyclical pressure on bank capital positions associated with Basel II is of almost the same order of magnitude as the preexisting baseline effect under Basel I." Recall that the shortfall of the capital positions under Basel I can be thought of as solely due to the increase in the shadow cost of capital.

${ }^{21}$ The integrals associated with the aggregate shock are numerically calculated by using the Gauss-Hermite quadrature with 5 nodes. The integrals associated with the liquidity shock are calculated by using Simpson's rule with 51 nodes, since the distribution is truncated by $\bar{\omega}$.
} 


\section{Table 4: Steady-State Effects of Higher Capital Requirement}

\begin{tabular}{ll|ll}
\hline \hline Output & -0.07 & Net worth & -0.07 \\
Capital stock & -0.29 & Liquidity dependence & -0.02 \\
Investment & -0.29 & PD & +0.01 \\
Total loans & -0.27 & Price of capital & +0.22 \\
\hline \hline
\end{tabular}

Notes: Table reports percentage changes of each variable (except PD) when the capital requirement ratio is raised from $8 \%$ to $12 \%$. The change in PD is expressed as percentage points.

helps us gain insights into the underlying mechanism of the main results in the subsequent section.

\subsection{Permanent Increase}

Level effects. We first consider the effects when the capital requirement ratio is raised from $8 \%$ to a permanently higher level, $12 \%$. The effects on the key macro variables are summarized in Table 4. Since the higher capital requirement imposes a higher cost for financial intermediation, it reduces the total number of loans and liquidity dependence. The increase in PD reflects the fact that the higher capital requirement makes it more difficult for the bank-entrepreneur relationship to withstand the liquidity shock, meaning that more positive NPV projects are abandoned. This directly affects aggregate investment and the capital stock. The effect on aggregate output amounts to $0.07 \%$. Finally, because supply of the capital good declines, the price of capital increases. ${ }^{22}$

We would like to stress that the level effects highlighted here should be interpreted with caution because, as we mentioned above, our model takes into account only the costly aspects of capital requirements. For instance, higher capital requirements advocated in the aftermath of the recent financial crisis play a useful role in avoiding bank failures, which could result in significant negative effects on the macroeconomy. Our model has nothing to say about the possible benefits of higher capital requirements because there is no bank failure in our setup.

Transition dynamics. Figure 1 presents the transition dynamics from the initial steady state to the new steady state. Interestingly, before reaching the new steady state, some variables go through larger declines, exhibiting (inverse) hump-shaped patterns. In particular, additional declines in investment and total loans are most noticeable, whereas the path of output shows only a modest hump. The reason for this larger decline in investment is owing

\footnotetext{
${ }^{22}$ To save space, we did not report the effects on consumption and the interest rate. But not surprisingly, aggregate consumption declines and the interest rate increases.
} 
(a) Total loans

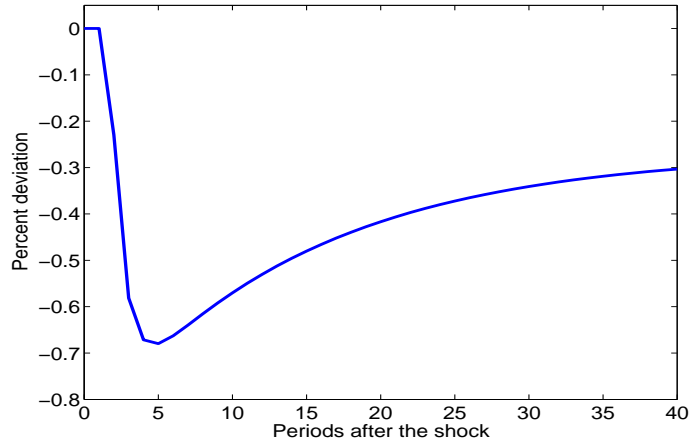

(c) Net worth

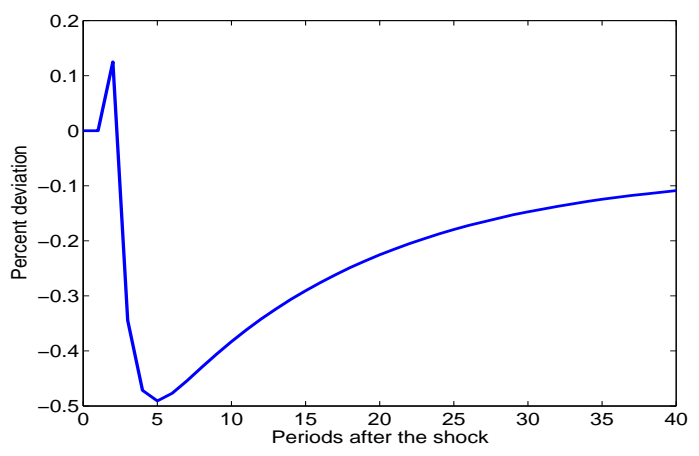

(e) Price of capital

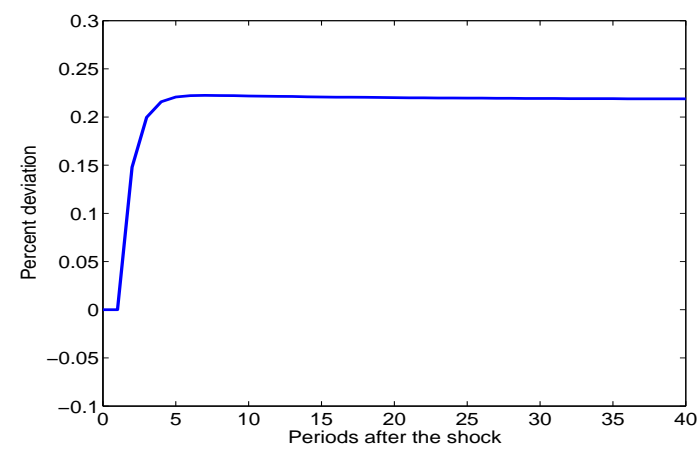

(b) Liquidity dependence

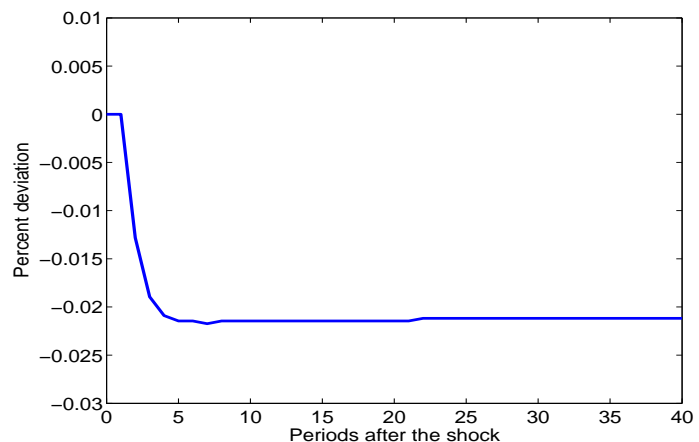

(d) Investment

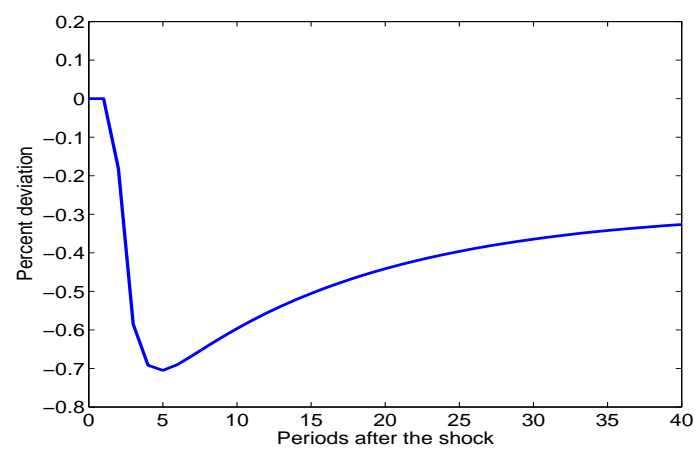

(f) Output

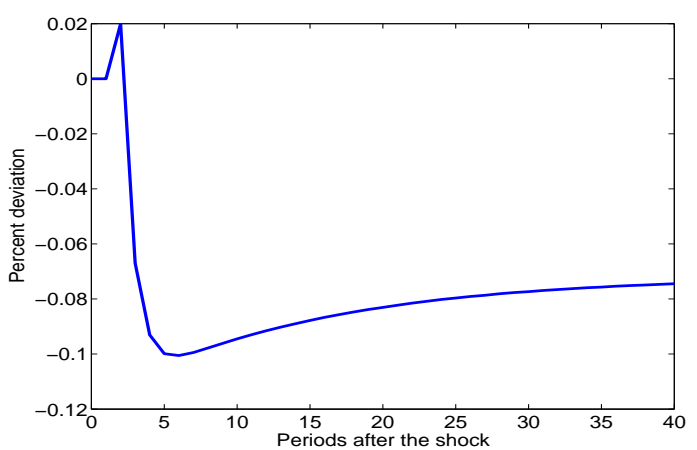

Figure 1: Responses to a Permanently Higher Capital Requirement

Notes: Plotted are transition paths in response to a permanent increase in the capital requirement ratio from $8 \%$ to $12 \%$.

to the household's substitution from savings into consumption. As mentioned in footnote 22, aggregate consumption eventually reaches a permanently lower level. However, it increases initially because the substitution effect is large enough. ${ }^{23}$ This substitution effect results mainly from the increasing price of capital.

\footnotetext{
${ }^{23}$ Aggregate consumption is largely driven by households' consumption because the share of entrepreneurs' consumption is very small in the model.
} 
(a) Total loans

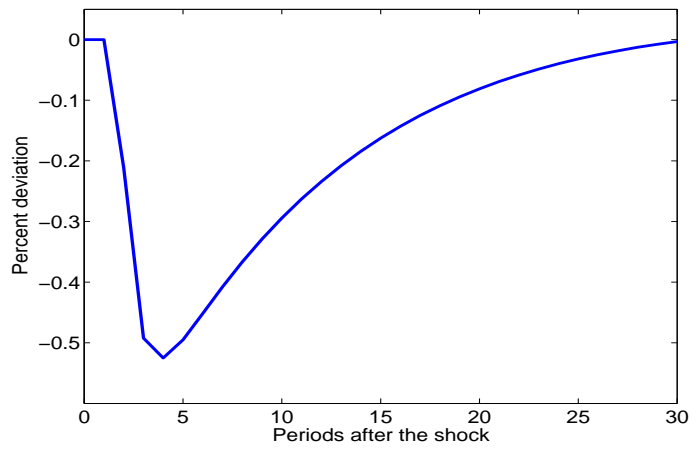

(c) Net worth

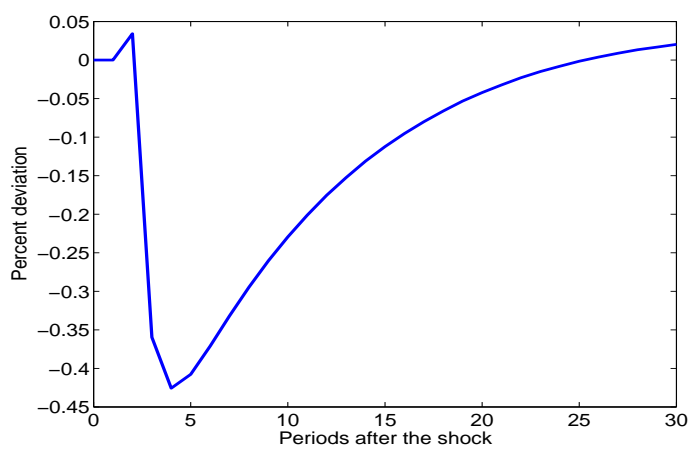

(e) Price of capital

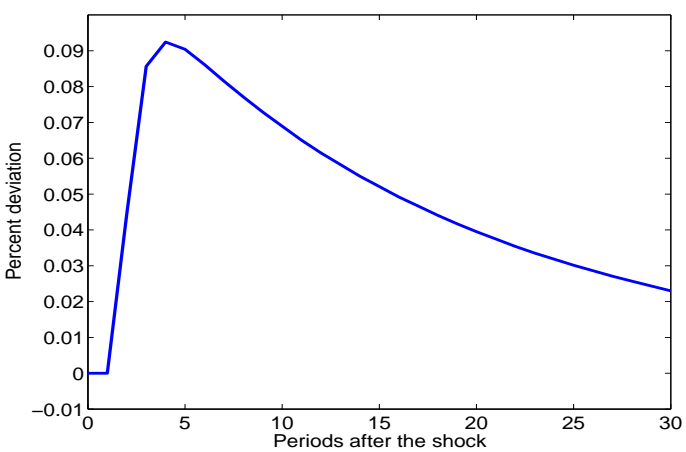

(b) Liquidity dependence

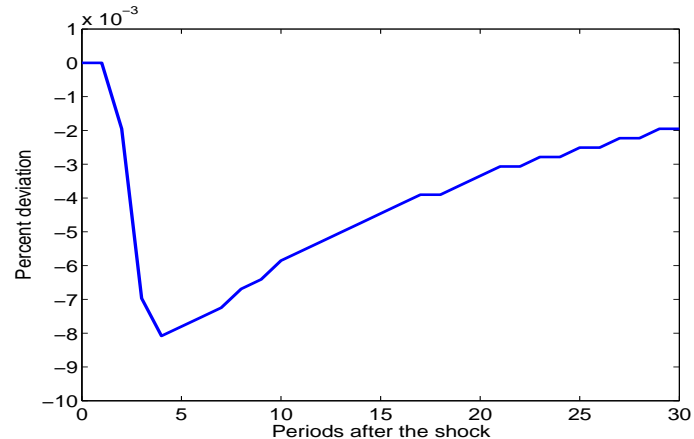

(d) Investment

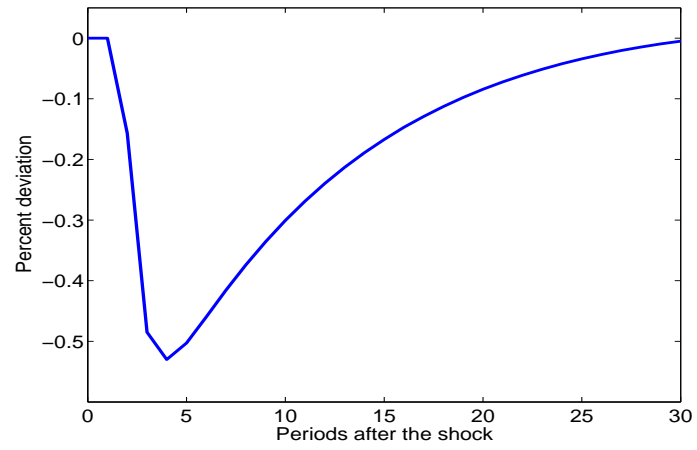

(f) Output

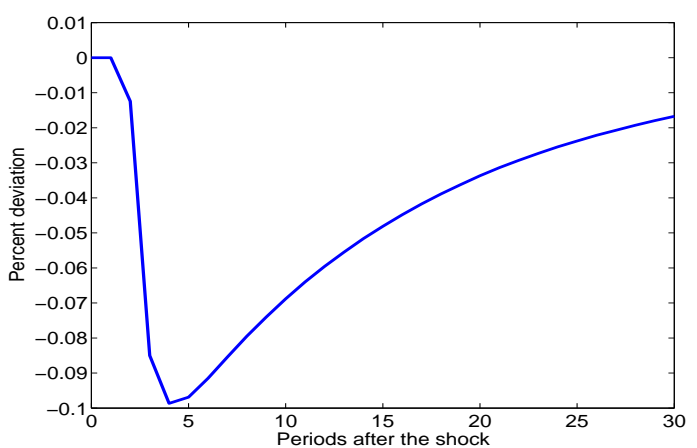

Figure 2: Responses to a Temporary Capital Requirement Shock

Notes: Plotted are responses to an increase in the capital requirement ratio. The requirement ratio goes up from $8 \%$ to $10 \%$ in the impact period and returns to $8 \%$ with a persistence parameter of 0.95 .

\subsection{Transitory Shock}

We now consider an experiment in which the capital requirement ratio follows a transitory persistent process (i.e., an $\mathrm{AR}(1)$ process). Figure 2 presents the responses to this shock. Note that, in this experiment, the capital requirement ratio initially increases to $10 \%$ and gradually returns to the steady-state level of $8 \%$ with the persistence parameter of 0.95 .

Due to the increase in the capital requirement and because equity is more costly than de- 
posits, the number of loans decrease by about $0.16 \%$ relative to its steady-state value (Panel (a)). The liquidity dependence variable declines slightly from its steady-state value (Panel (b)). Note that, as mentioned elsewhere, this decline of liquidity dependence, while small in this experiment, represents the feature of the model that the higher capital requirement makes it more difficult for banks to finance positive NPV projects. Further, a higher cost of funds translates into declines in entrepreneurs' net worth and hence decreases in investment (Panels (c) and (d)). The price of capital increases because the higher capital requirement decreases the supply of the capital good (Panel (e)), as was discussed in the previous subsection. Aggregate output decreases in a hump-shaped manner (Panel (f)), mainly reflecting the behavior of investment. Aggregate consumption (not shown in the figure) initially increases and then declines before going back to the steady state. ${ }^{24}$

\section{Procyclicality of Bank Capital Regulation}

This section presents the main results of this paper, quantifying the procyclical effects of bank capital requirements. We first briefly summarize the quantitative properties of the model without the capital requirement. The procyclicality of capital requirements are then analyzed in the two regulatory regimes.

\subsection{Dynamics in the No-Requirement Economy}

We first briefly discuss the dynamics of the model without imposing the capital requirement. Given our assumption that equity issuance is costly (with no benefits), banks hold no equity in this case. ${ }^{25}$ Figure 3 presents the responses to a one-standard-deviation negative aggregate productivity shock in this economy.

Since this economy is already analyzed by Kato (2006), we will be brief and emphasize the results particularly relevant to our paper. In our view, a key feature of this model is the behavior of liquidity provision by banks in the wake of an adverse shock. In particular, observe that the firm's liquidity dependence increases when the negative shock occurs. That is, it is optimal for the bank to increase the liquidity dependence, allowing entrepreneurs to better withstand their liquidity needs in bad times. Naturally, aggregate loan demand falls in response to the negative shock since the marginal product of capital falls. However, the increase in liquidity dependence dampens the impact of the productivity shock on output. As emphasized by Kato (2006), this "smoothing" mechanism generates a hump-shaped response in aggregate output. ${ }^{26}$

\footnotetext{
${ }^{24}$ This behavior can be understood by the behavior of the price of capital and the substitution effect discussed above.

${ }^{25}$ Our calibration assumes the presence of the capital requirement and associated equity issuance cost. To solve the no-requirement economy, we simply set the capital requirement to zero. This had minimal impacts on the steady state values of the model presented in Table 3.

${ }^{26}$ Kato (2006) compares output responses in his model and the standard RBC model and shows that the RBC model implies a larger initial response of output. While our model differs from Kato's in terms of calibration as well as the model itself, we also obtain the hump-shaped response.
} 
(a) Total loans

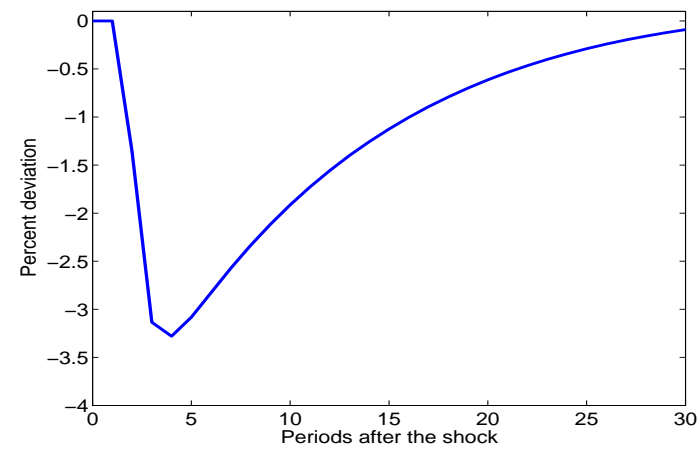

(c) Net worth

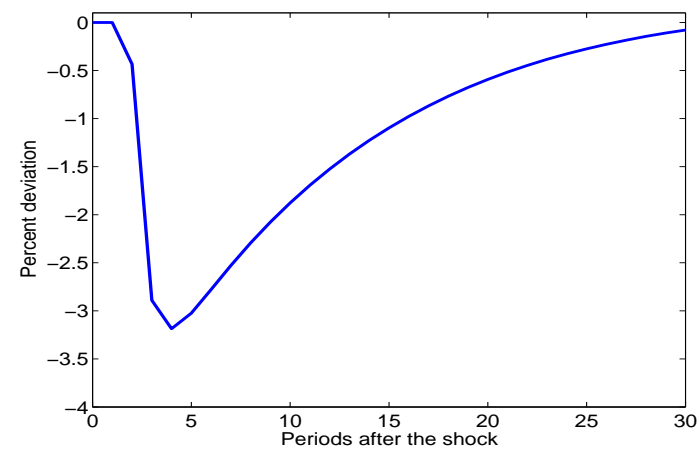

(e) Price of capital

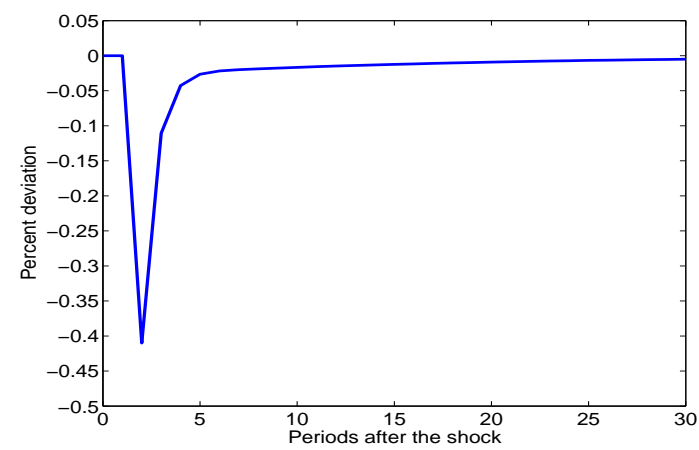

(b) Liquidity dependence

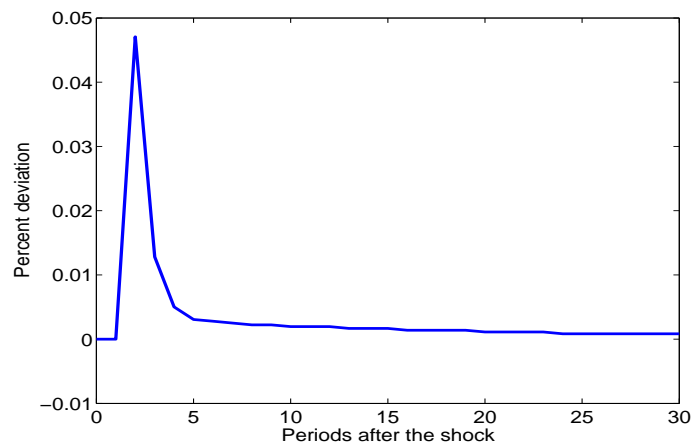

(d) Investment

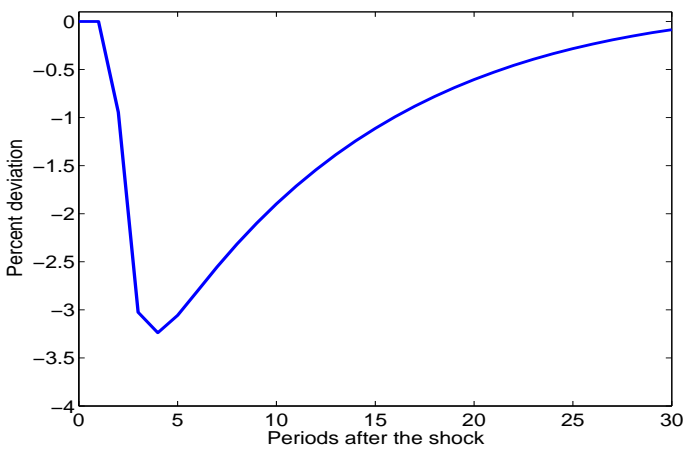

(f) Output

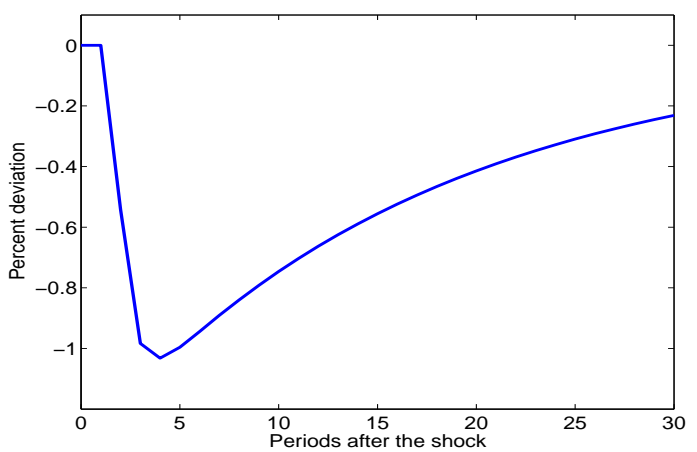

Figure 3: Responses to a Productivity Shock

Notes: Plotted are responses to a one-standard-deviation negative productivity shock. The capital requirement ratio and the equity issuance cost are held fixed at $8 \%$ and 10\%, respectively.

\subsection{Impulse Responses}

We now consider the exercises to quantify the procyclicality induced by the two forms of capital requirements. We link the TFP series with the capital requirement ratio and the equity issuance cost through Equations (27) and (28), respectively. Remember that these specifications assume that the two variables are perfectly correlated (negatively) with the aggregate productivity series. It is informative to see how they behave relative to aggregate 


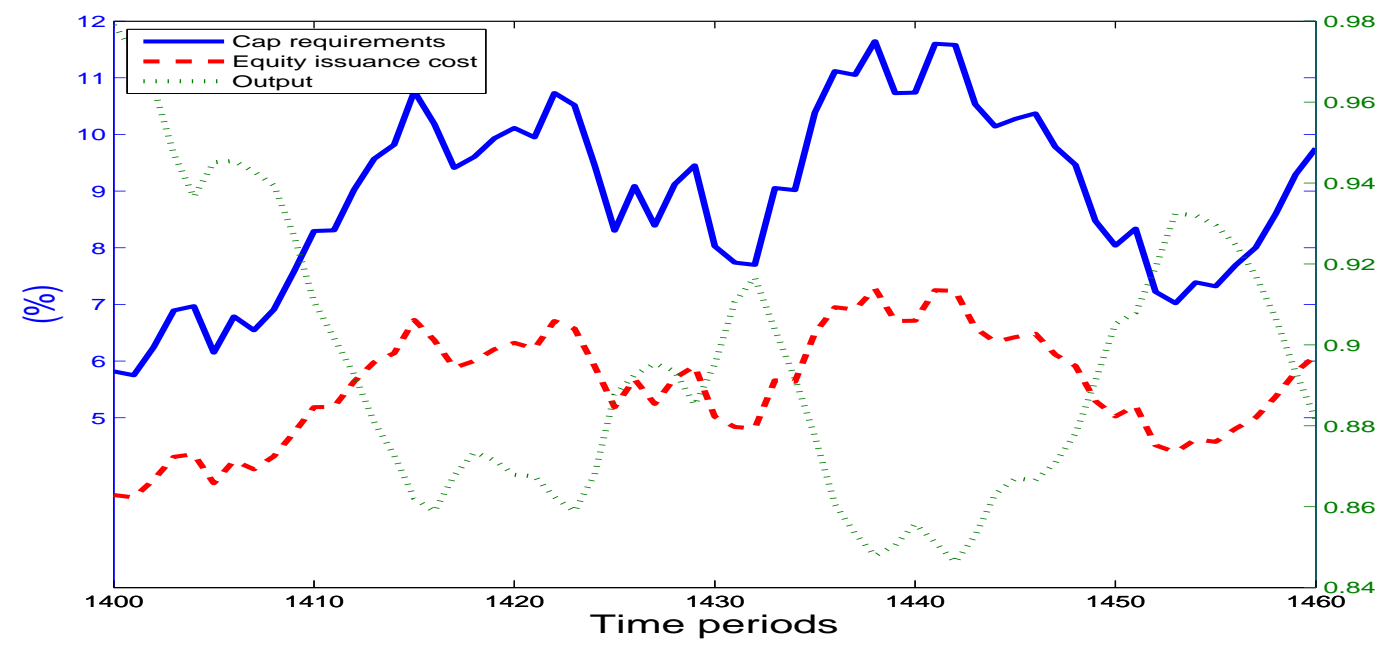

Figure 4: Sample Paths of Capital Requirements and Aggregate Output

Notes: Plotted are simulated series of the capital requirement ratio (applied only in the Basel II regime), the equity issuance cost (applied in both regimes) and the aggregate output series. The output series is the one generated under the economy with no capital requirement and measured along the right axis.

output in our economy. Figure 4 compares the two series with aggregate output generated under the benchmark model. The figure shows that the Basel II capital requirement ratio takes its highest value at around $11 \%$ and its lowest value at around $6 \%$ over the 15 -year simulation period. The variability of this series appears to be plausible, since it is obtained using the available empirical evidence in the risk-weight formula of Basel II. The figure also plots our simulated series for the equity issuance cost. As implied by our calibration, it has the same proportional amplitude as the capital requirement ratio.

Figure 5 shows how differently the economy responds to a negative TFP shock under the different regulatory regimes. Recall that the benchmark economy imposes no capital requirements. Figure 5 plots responses of household consumption and labor supply as well as the same six variables considered before. Panel (a) shows that the number of loans fall more under the presence of the capital requirements; at the lowest point in the responses, which occur in the third quarter, the differences from the benchmark economy amount to 12 basis points and 20 basis points under Basel I and Basel II, respectively. Panel (b) shows the differences in liquidity dependence. Remember that the model's key feature is that the entrepreneurs become more dependent of credit lines in bad times. Tighter capital requirements make the liquidity dependence more difficult. Interestingly, the peak responses under the three cases, which occur in the impact period, are very close with each other. However, capital requirements play a role in depressing the persistence of this variable.

The second row of Figure 5 shows the responses of the entrepreneur's net worth and investment in the three economies. In line with the larger declines in lending under Basel II, declines in entrepreneurial net worth and investment are also more accentuated in that 
(a) Total loans

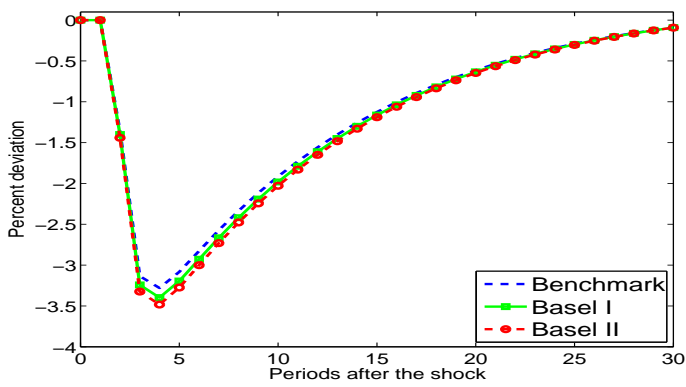

(c) Net worth

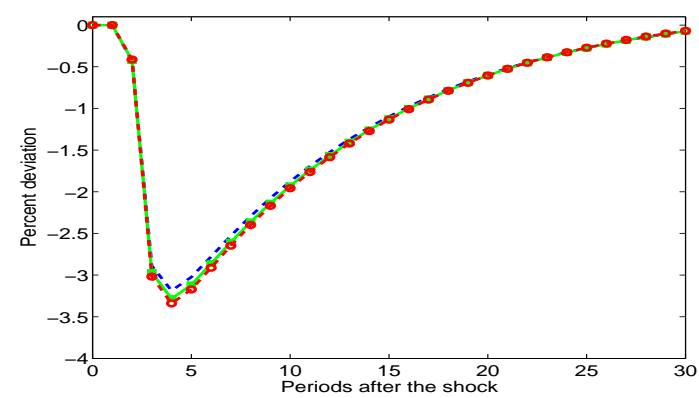

(e) Output

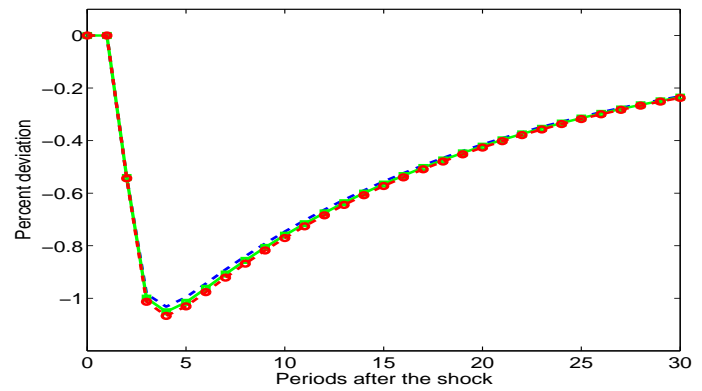

(g) Household consumption

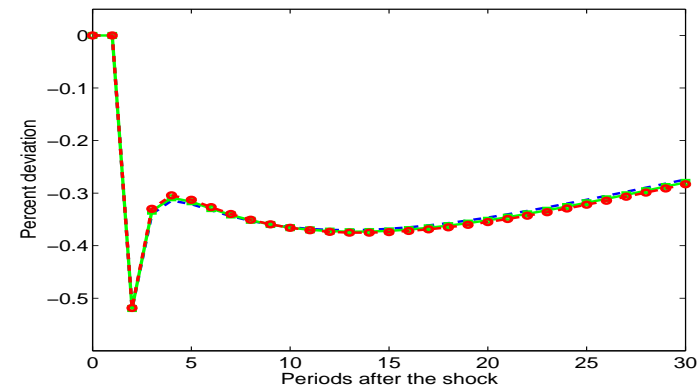

(b) Liquidity dependence

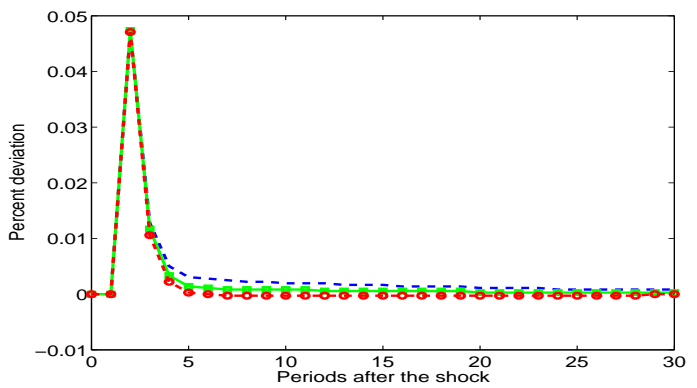

(d) Investment

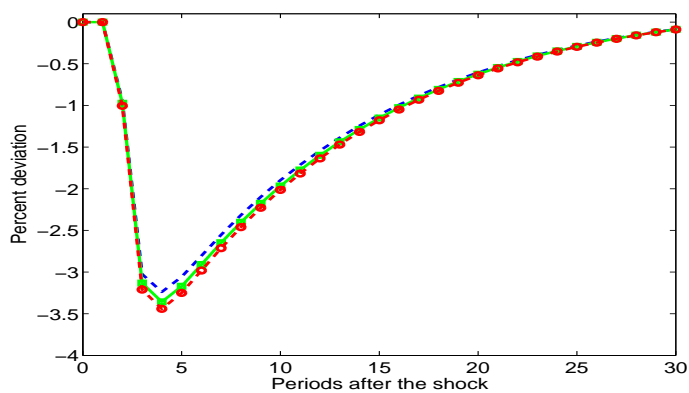

(f) Price of capital

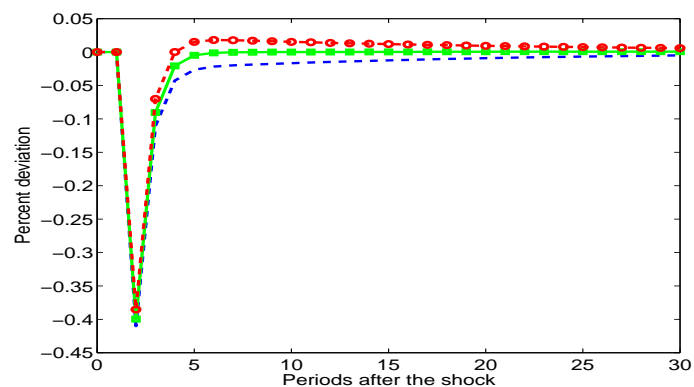

(h) Labor supply

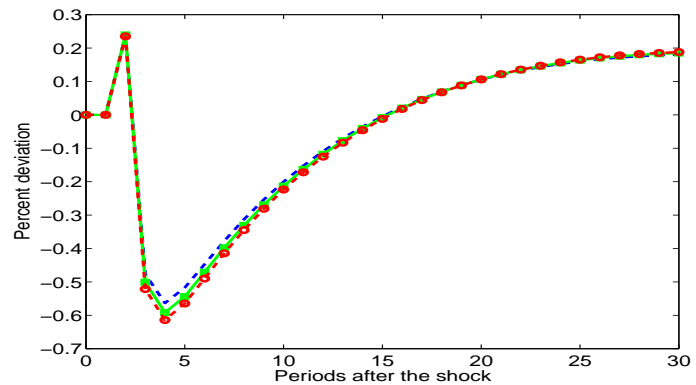

Figure 5: Procyclical Effects of Basel I and Basel II

Notes: Plotted are responses to a one-standard-deviation negative TFP shock under the three economies; in the benchmark economy, $\theta_{t}=0.08$ and $\gamma_{t}=0.05$; in the Basel I economy, $\theta_{t}=0.08$ and $\gamma_{t}=0.05 A_{t}^{-8}$; in the Basel II economy, $\theta_{t}=0.08 A_{t}^{-8}$ and $\gamma_{t}=0.05 A_{t}^{-8}$. 
case. Because equity is more costly than deposits, the increases in the capital requirement and equity issuance cost in bad times raise the costs of external funds to entrepreneurs. Consequently, entrepreneurial profits and thus net worth are reduced by more under Basel II. The differences in declines in investment are significant; the declines are amplified by 12 basis points and 20 basis points at its trough, which occurs in the third quarter after the shock hits the economy.

The third row presents the responses of output and the price of capital. The output responses are hump-shaped across all cases. Again, the fall of output is most significant under Basel II. At the trough of the economy, the differences from the benchmark model amount to 2 basis points and 3 basis points in Basel I and Basel II, respectively. This can be considered relatively small. One important issue to remember, however, is that these are the differences with respect to a one-standard deviation shock. In a more severe recession, the differences can be significantly larger. We will come back to this issue below again. As for the behavior of the price of capital, observe that the pattern of the responses is reversed. That is, declines in the price of capital are smallest under Basel II. It even goes above its steady-state level several periods after the shock. Remember that the higher capital requirement itself raises the price of capital, since it reduces the supply of capital goods. Thus, declines in the price of capital in the face of the negative productivity shock are mitigated under this regime.

The responses of household consumption, presented in Panel (g) are more nuanced; first of all, the differences are difficult to observe; second, after sharp declines in the impact period, which are of the same magnitude across all three cases, consumption recovers more under Basel II. This stems from the behavior of the price of capital; upward trajectories of the price of capital from the second period on are most pronounced in that case, inducing the steepest recovery in consumption (see the discussion in Subsection 4.1). However, the differences in the behavior of consumption are relatively small. Last, Panel (h) shows that the largest declines in labor supply occur under Basel II.

\subsection{Output Volatility}

The first row of Table 5 translates the impulse responses in output into unconditional standard deviations. The numbers are based on logged HP-filtered series. When the economy moves from the benchmark no-requirement economy to the Basel I economy, output volatility increases from $1.84 \%$ to $1.87 \%$. Moving to the Basel II economy raises the volatility to $1.92 \%$.

The remaining rows of Table 5 present the comparisons with cases where the elasticity of the equity issuance cost is set to larger negative values. Note first that in the baseline calibration with $\gamma_{1}=-8$, the equity issuance cost fluctuates within a relatively narrow range as can be seen in Figure 4; the standard deviation of the series is $0.9 \%$ and a three standarddeviation upward move raises the equity issuance cost to roughly $8 \%$ from $5 \%$. When the fluctuations of the equity issuance cost are raised by using alternative elasticities -12 and -15 , the three-standard deviation upward moves from the mean correspond, respectively, to $9.3 \%$ and $10.4 \%$. The table shows that the volatility difference between the no-requirement 
Table 5: Output Volatility

\begin{tabular}{lccc}
\hline \hline & No Requirement & Basel I & Basel II \\
\hline \multirow{2}{*}{ Baseline $\left(\gamma_{1}=-8\right)$} & 1.84 & 1.87 & 1.92 \\
& - & $(1.016)$ & $(1.043)$ \\
$\gamma_{1}=-12$ & - & 1.89 & 1.94 \\
& - & $(1.027)$ & $(1.054)$ \\
$\gamma_{1}=-15$ & - & 1.91 & 1.97 \\
& - & $(1.038)$ & $(1.071)$ \\
\hline \hline
\end{tabular}

Notes: Results are based on 500 replications of 200 observations (after randomization of the initial condition). The standard deviations are based on logged HP-filtered series with a smoothing parameter of 1,600. Numbers in parentheses report relative volatilities compared to that under the economy with no capital requirement.

economy and the Basel II economy (Basel I economy) can reach more than 10 (5) basis points when the elasticity is set larger than $\gamma_{1}=-12$.

\subsection{Effects During Booms and Downturns}

Note that differences in the standard deviations convey only the information regarding the average effect. Perhaps more interesting are the differences in output paths under different regulatory environments during booms and downturns. More specifically, we simulate a long time series (10,000 observations) of aggregate output in the three regulatory environments; economies with (i) no capital requirement, (ii) the Basel I regulation, and (iii) the Basel II regulation, feeding the same sequence of the underlying driving process. We then calculate differences in logged HP filtered output series at each period. Let $y_{t}^{B 0}, y_{t}^{B 1}$, and $y_{t}^{B 2}$ represent these output series in the no-requirement economy, the Basel I economy, and the Basel II economy, respectively. Figure 6 plots a randomly-chosen sample of 200 quarterly observations of $\left(y_{t}^{B 1}-y_{t}^{B 0}\right) 100$ and $\left(y_{t}^{B 2}-y_{t}^{B 0}\right) 100$ under the baseline calibration $\left(\gamma_{1}=-8\right)$. These series capture the effects of Basel I and Basel II relative to no capital requirement. As can be seen, the average differences can be relatively small: The mean absolute deviations of the 10,000 observations are 4 basis points and 7 basis points, respectively. However, the graph also shows that there are several occasions in this 20 year period, in which the deviations are quite pronounced. For example, there are two instances where the effect of Basel II exceeds 25 basis points.

To systematically quantify these infrequent, yet important events, Table 6 presents the 1st, 5th, 95th, 99th percentiles of the distributions of differences in output. Note that the lower part of the distribution (1st percentile and 5th percentile) capture the effects during 


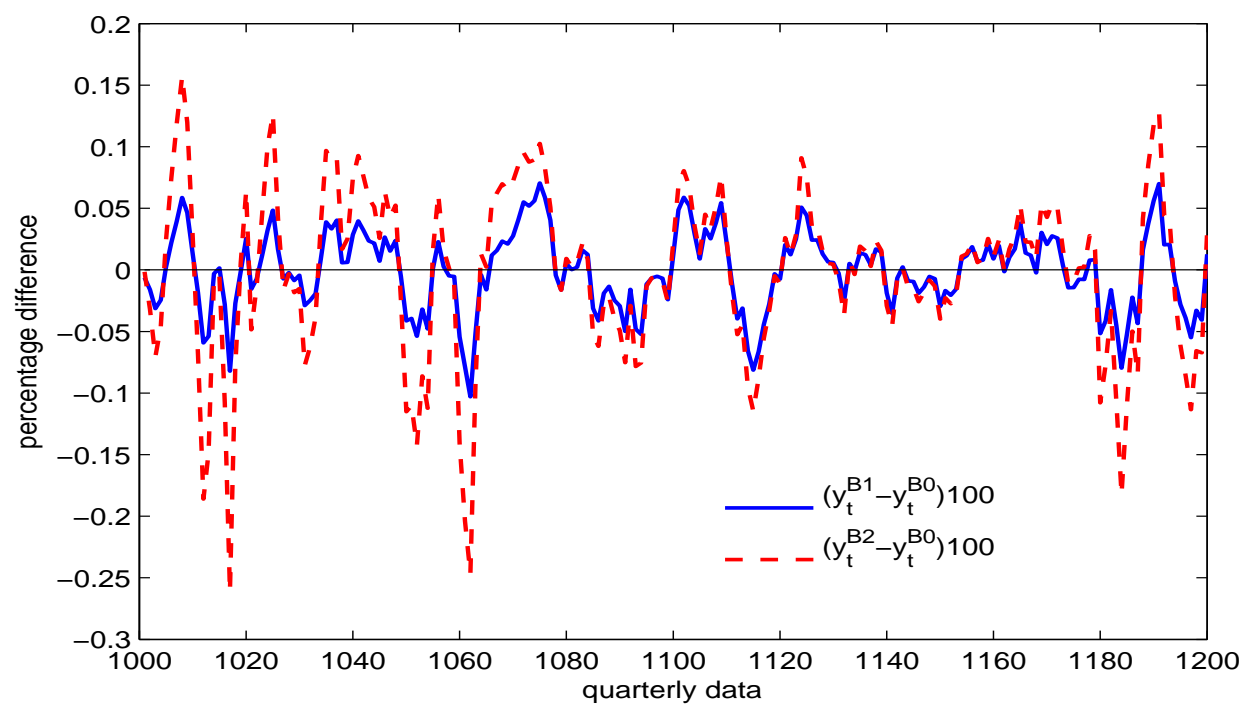

Figure 6: Sample Paths of Differences in Output $\left(\gamma_{1}=-8\right)$

Notes: The graph plots the sample paths (200 quarterly observations) of output differences, expressed as log differences times 100. $y_{t}^{B 0}, y_{t}^{B 1}$, and $y_{t}^{B 2}$ are logged HP filtered output series in the no-requirement economy, the Basel I economy, and the Basel II economy, respectively.

downturns and the upper part corresponds to the effects during booms. ${ }^{27}$ Let us focus on the lower tail of the distributions. Under the baseline calibration with $\gamma_{1}=-8$, the 1st percentile of the distribution amounts to 12 basis points when Basel I and no-requirement economies are compared. The magnitude goes up to 40 basis points in the comparison of Basel II and no requirement economies. It is true that these numbers correspond to the effects during the "rare" episodes. ${ }^{28}$ However, even when we consider the 5th percentile, output differences are not trivial, especially when the Basel II economy is compared with the no-requirement economy. The second and third panels of Table 6 present the results from the same calculations under larger elasticities. The results indicate that the procyclicality induced by capital requirements are indeed sizable especially during severe downturns. Overall, the procyclical effects of Basel I and Basel II amount to 10-15 basis points and 20-40 basis points, respectively.

\subsection{Countercyclical Regulation}

Recently both policy makers and academics have been advocating changes to Basel II by explicitly making bank capital regulation countercyclical to mitigate procyclicality (see, for

\footnotetext{
${ }^{27}$ Observe that the distributions are somewhat asymmetric. This asymmetry simply comes from the fact that the equity issuance cost is bounded by zero by construction of the process.

${ }^{28}$ Note that it is somewhat misleading to interpret 1st and 99th percentiles as once-every-100-quarter (25-year) events because these events tend to occur in a cluster given that the driving process is persistent. These events, however, do occur every 40-50 years in our simulated series.
} 
Table 6: Output Differences in Booms and Downturns

\begin{tabular}{cc|rrrr}
\hline \hline \multicolumn{2}{c}{ Percentiles } & 1 & 5 & 95 & 99 \\
\hline \multirow{4}{*}{ Baseline } & $\left(y_{t}^{B 1}-y_{t}^{B 0}\right) 100$ & -0.12 & -0.08 & 0.06 & 0.09 \\
& $\left(y_{t}^{B 2}-y_{t}^{B 0}\right) 100$ & -0.40 & -0.18 & 0.15 & 0.25 \\
& $\left(y_{t}^{B 2}-y_{t}^{B 1}\right) 100$ & -0.27 & -0.11 & 0.09 & 0.17 \\
\hline \hline \multirow{5}{*}{$\gamma_{1}=-12$} & $\left(y_{t}^{B 1}-y_{t}^{B 0}\right) 100$ & -0.22 & -0.12 & 0.10 & 0.15 \\
& $\left(y_{t}^{B 2}-y_{t}^{B 0}\right) 100$ & -0.61 & -0.24 & 0.20 & 0.38 \\
& $\left(y_{t}^{B 2}-y_{t}^{B 1}\right) 100$ & -0.39 & -0.13 & 0.11 & 0.25 \\
\hline \hline \multirow{4}{*}{$\gamma_{1}=-15$} & $\left(y_{t}^{B 1}-y_{t}^{B 0}\right) 100$ & -0.32 & -0.16 & 0.13 & 0.21 \\
& $\left(y_{t}^{B 2}-y_{t}^{B 0}\right) 100$ & -0.83 & -0.30 & 0.25 & 0.53 \\
& $\left(y_{t}^{B 2}-y_{t}^{B 1}\right) 100$ & -0.51 & -0.14 & 0.14 & 0.34 \\
\hline \hline Notes:
\end{tabular}

Notes: The table reports output paths under the three regulatory environments that are hit by the same sequence of the underlying shock. Results are based on a long time series (10,000 observations) of logged and HP filtered data. Each reported number is the log difference (multiplied by 100) at each percentile of the distribution. $y_{t}^{B 0}, y_{t}^{B 1}$, and $y_{t}^{B 2}$ are logged HP filtered output series under no capital requirement, the Basel I capital requirement and the Basel II capital requirement, respectively.

example, Gordy and Howells (2006)). We can examine this hypothetical policy by simply changing the process for the capital requirement specified in Equation (27); we can assume that the capital requirement goes up during booms and down during downturns by setting $\theta_{1}$ to a positive value.

However, since we do not have a way to tightly set this parameter for this hypothetical economy, we do not examine its quantitative implications. We can, however, easily infer the implications of such experiments from the results presented above. Observe that within our model, countercyclical regulation can be used to completely offset the fluctuations in the equity issuance cost, so that the economy traces the paths of the benchmark economy even when the equity issuance cost moves countercyclically. ${ }^{29}$ Remember that we motivated the idea of time-varying equity issuance cost by referring to the evidence of Kashyap and Stein (2004) that the shadow cost of bank capital goes up during downturns. These authors, in fact, argue for countercyclical regulation, that is, relaxing the required capital ratio when the cost of maintaing bank capital is high.

\footnotetext{
${ }^{29}$ This is achieved by setting $\theta_{1}=8$ (instead of -8 ). See Equation (29).
} 


\section{Conclusion}

In this paper, we have quantified the procyclical effects of bank capital requirements. Relative to previous studies, our analysis is based on a general equilibrium model where capital goods production is subject to the agency problem studied by Holmstrom and Tirole (1998). We find that, across various plausible calibrations, Basel I and Basel II contribute to increasing the standard deviation of output fluctuations by around 5 basis points and 10 basis points, respectively. The magnification effect can be significantly larger around business cycle peaks and troughs.

Many simplifying assumptions we made allowed us to quantify the macroeconomic effects of bank capital requirements in a general equilibrium model. Our model thus misses several aspects that are considered important in the earlier literature. First, as mentioned elsewhere, the way we impose capital requirements is very stylized. In particular, our model lacks a mechanism that generates a precautionary capital buffer and thus capital requirements are always binding. As explored in Repullo and Suarez (2009), incorporating this "smoothing" motivation can alter the quantitative assessment of the procyclical effects. Second, we a priori assumed the existence of capital requirements without modeling why bank capital regulation exists to begin with. In this regard, capital requirements can be motivated as a device limiting the bank's moral hazard under the presence of deposit insurance as in Van den Heuvel (2008). Introducing the welfare -improving aspects of capital requirements

could allow us to conduct a more serious welfare analysis. Extending the model along these dimensions is an important avenue for future research.

\section{Appendix}

The internal ratings based (IRB) approach uses the probability of default, the loss given default, the exposure at default, and maturity for each exposure to calculate the bank's capital requirement for each loan (see Basel Committee on Banking Supervision (2004)). The capital requirement ratio is derived from the following formula:

$$
\begin{array}{r}
\text { Capital Requirement }{ }_{t}=L G D \times\left[N\left(\frac{N^{-1}\left(P D_{t}\right)+\sqrt{C_{t}} \times N^{-1}(0.999)}{\sqrt{1-C_{t}}}\right)-P D_{t}\right] \\
\times\left(\frac{1+(M-2.5) \times b_{t}}{1-1.5 \times b_{t}}\right),
\end{array}
$$

where $N($.$) is the distribution function of standard normal, P D$ is the probability of default, $L G D$ is loss given default, and $M$ is average maturity of loans. $C$ is called the correlation factor is linked with $P D$ through the following expression:

$$
C_{t}=0.12+0.12 \times \exp ^{-50 \times P D_{t}} .
$$

Finally, there is a parameter, $b$, which adjusts the maturity of the loan according to its risk as found in various quantitative impact studies conducted by banks as requested by national 
supervisors and the Basel Committee. This parameter is defined as follows:

$$
b_{t}=\left[0.11852-0.0547 \times \log \left(P D_{t}\right)\right]^{2} .
$$

\section{References}

Araten, M., M. Jacobs JR. And P. Varshney, "Measuring LGD on Commercial Loans: An 18-Year Internal Study," The Risk Management Association Journal 86 (2004), 96-103.

Basel Committee on Banking Supervision, "International Convergence of Capital Measurement and Capital Standards: A Revised Framework," (June 2004).

Bernanke, B. And M. Gertler, "Agency Costs, Net Worth, and Business Fluctuations," American Economic Review 79 (1989), 14-31.

Bernanke, B., M. Gertler and S. Gilchrist, "The Financial Accelerator in a Quantitative Business Cycle Framework," in J. Taylor and M. Woodford, eds., Handbook of Macroeconomics volume 1, chapter 21 (Elsevier, 1999), 1341-1393.

Blum, J. And M. Hellwig, "The Macroeconomic Implications of Capital Requirements for Banks," European Economic Review 39 (1995), 739-749.

Carlstrom, C. and T. Fuerst, "Agency Costs, Net Worth, and Business Fluctuations: A Computable General Equilibrium Analysis," American Economic Review 87 (December 1997), 893-910.

Chen, N.-K., "Bank Net Worth, Aseet Prices and Economic Activity," Journal of Monetary Economics 48 (October 2001), 415-436.

Cooley, T. And V. Quadrini, "Financial Markets and Firm Dynamics," American Economic Review 91 (2001), 1286-1310.

Covas, F. And W. Den HaAn, "The Role of Debt and Equity Finance over the Business Cycle," Unpublished manuscript, March 2010.

Dorefeenko, V., G. Lee And K. Salyer, "Time-Varying Uncertainty and the Credit Channel," Bulletin of Economic research 60 (2008), 375-403.

Gordy, M. And B. Howells, "Procyclicality in Basel II: Can We Treat the Disease Wthout Killing the Patient?," Journal of Financial Intermediation 15 (July 2006), 395417.

HeID, F., "The Cyclical Effects of the Basel II Capital Requirements," Journal of Banking and Finance 31 (2007), 3885-3900.

Holmstrom, B. And J. Tirole, "Financial Intermediation, Loanable Funds and the Real Sector," Quarterly Journal of Economics 112 (1997), 663-691. 
—_ "Private and Public Supply of Liquidity," Journal of Political Economy 106 (February 1998), 1-40.

Kashyap, A., R. Rajan and J. Stein, "Banks as Liquidity Providers: An Explanation for the Co-existence of Lending and Deposit-Taking," Journal of Finance 57 (2002), 33-74.

Kashyap, A. And J. Stein, "Cyclical Implications of the Basel II Capital Standards," Federal Reserve Bank of Chicago Economic Perspectives 1Q (2004), 18-31.

Kato, R., "Liquidity, Infinite Horizons and Macroeconomic Fluctuations," European Economic Review 50 (July 2006), 1105-1130.

Men, C. And K. Moran, "The Role of Bank Capital in the Propagation of Shocks," Journal of Economic Dynamics and Control 34 (2010), 555-576.

Repullo, R. And J. Suarez, "The Procyclical Effects of Bank Capital Regulation," Unpublished manuscript, CEMFI, 2009.

Schuermann, T., "Hearing on Commercial \& Industrial and Commercial Real Estate Lending," (2009), testimony before the Congressional Oversight Panel for the Troubled Asset Relief Program.

Sufi, A., "Bank Lines of Credit in Corporate Finance: An Empirical Analysis," Review of Financial Studies 22 (2009), 1057-1088.

Townsend, R., "Optimal Contracts and Competitive Markets with Costly State Verification," Journal of Economic Theory 21 (1979), 265-93.

Van den Heuvel, S., "The Welfare Cost of Bank Capital Rquirements," Journal of Monetary Economics 55 (March 2008), 298-320.

_, "The Bank Capital Channel of Monetay Policy," Unpublished manuscript, August 2009.

ZHu, H., "Capital Regulation and Banks' Financial Decisions," International Journal of Central Banking 4 (2008), 165-211. 